\title{
Crop production changes and the impact of Grain for Green program in the Loess Plateau of China
}

\author{
LYU Changhe ${ }^{1,2 *}$, XU Zhiyuan ${ }^{1,2,3}$ \\ ${ }^{1}$ Key Laboratory of Land Surface Pattern and Simulation, Institute of Geographic Sciences and Natural Resources Research, \\ Chinese Academy of Sciences, Beijing 100101, China; \\ ${ }^{2}$ College of Resources and Environment, University of Chinese Academy of Sciences, Beijing 100049, China; \\ ${ }^{3}$ Institute of Rural Development, Zhejiang Academy of Agricultural Sciences, Hangzhou 310021, China
}

\begin{abstract}
Since the Grain for Green (GFG) program was implemented in 1999, most steeply sloping farmlands in the Loess Plateau of China have been returned to forestland and grassland. To understand its impact on the food production, this study analyzed the spatiotemporal changes of food crop production (FCP) in the plateau and quantified the contribution of sown area and yield changes to the total FCP during 1998-2014 using factor decomposition models, and then discussed the impact of GFG program on the FCP based on literature data. With the implementation of GFG program, total sown area in the Loess Plateau quickly deceased by $17.3 \%$ from 1998 to 2003 , and then gradually restored to $1.03 \times 10^{7} \mathrm{hm}^{2}$ in 2010 . Thereafter, it slightly decreased to $1.02 \times 10^{7} \mathrm{hm}^{2}(94.6 \%$ of the area in 1998) in 2014. By contrast, total FCP generally showed an apparent growth trend, averagely increased by $1.71 \%$ per year in the whole plateau during 1998-2014. This increase was jointly contributed by the improved yield of individual crops, and the adjustment of cropping structure, i.e., the expansion of high yield maize crop. The factor decomposition analysis results indicate that the sown area shrinkage only reduced the growth rate of total FCP by $0.29 \%$ per year during 1998-2014, although a significant impact was found for the early stage of 1999-2003. The results suggest that the implementation of GFG program would not induce an obvious risk of the food security. Therefore, it is suggested that the GFG program should be set as a long-term strategic policy, by not only supporting the conversion of slope farmlands, but also helping local farmers to seek sustainable ways of land use to improve the income and livelihood. It can be combined with the poverty eradication program, to simultaneously achieve the national goals of ecological civilization building and the livelihood improvement of rural people in the Loess Plateau. Considering rainfall limitation, the conversion of slope farmlands should be prioritized to grasslands.
\end{abstract}

Keywords: spatiotemporal change; farmland conversion; hilly region; factor decomposition; semi-arid regions

Citation: LYU Changhe, XU Zhiyuan. 2020. Crop production changes and the impact of Grain for Green program in the Loess Plateau of China. Journal of Arid Land, 12(1): 18-28. https://doi.org/10.1007/s40333-020-0091-9

\section{Introduction}

The Chinese Loess Plateau is well known for its severe soil erosion mainly resulted from overcultivation of slope lands. To mitigate the land degradation, the Chinese government has implemented the Grain for Green (GFG) program since August 1999, aiming at converting steeply sloping or marginal croplands to forestland and grassland. Acknowledging that the farmland conversion would have a significant impact on the food production and farmer's livelihood, the

\footnotetext{
*Corresponding author: LYU Changhe (E-mail: luch@igsnrr.ac.cn)

Received 2018-12-11; revised 2019-12-03; accepted 2019-12-09

C Xinjiang Institute of Ecology and Geography, Chinese Academy of Sciences, Science Press and Springer-Verlag GmbH Germany, part of Springer Nature 2020
} 
Chinese government has adopted the policy to supply subsidies of food grain/money to the farmers based on the converted area. This is why it is often called Grain for Green program.

Since the program implemented, its effects on the land use and environment have been explored and evaluated by numerous studies. Many of the studies indicate that the destroyed vegetation has been evidently restored (Zhou et al., 2009; Yue et al., 2014; Li and Lu, 2015; Li et al., 2016); thus the land use structure has been improved (Ran et al., 2010; Guo et al., 2015) and the soil erosion intensity has been greatly reduced (Fu et al., 2005; Zhao et al., 2013; Zuo et al., 2016; Yang and $\mathrm{Lu}, 2018$ ) in the Loess Plateau. Regarding its impacts on food production, Feng at al. (2005) estimated that the GFG implementation would cause a reduction of the total grain production by $10.0 \%-13.5 \%$ in the Loess Plateau based on three scenarios of slope farmland conversions. Xu et al. (2006) simulated the program impact, concluding that the GFG implementation would have a small impact on China's grain production. However, one study by Deng and Shangguan (2011) indicated that the program threated China's food security although it increased farmers' income. Another study by Liu and Li (2012) based on statistical data in 100 typical counties in the Loess Plateau found that the total grain production decreased during 1996-2007. In recent years, a number of studies analyzed the program effects on the farmers' livelihood based on household surveys for some counties in the Loess Plateau (Ye, 2009; Lu et al., 2011; Cheng, 2014; Han and Zhu, 2014; Zhu and Wang, 2014), but seldom specified to the whole plateau to analyze the GFG program impacts on the food crop production.

The GFG program has been implemented for nearly two decades. An analysis of changes in the total crop production and the sown area during the implementing period could contribute to understanding the GFG program effect. Therefore, we selected 1998-2014 as the study period, which the year 1998 represents the condition just before the GFG implemented in 1999 and 2014 represents the condition after the program has executed for 16 years in the Loess Plateau. Three specific objectives were addressed: the first was to detect variation trend in the total food crop production (FCP) and sown area during the period; the second was to quantify the contribution of the changes in crop yield, sown area and cropping structure to the FCP change using a factor decomposition analysis approach; and the third was to analyze the impact of GFG program on the FCP. We also explored the policy implications and suggestions. Considering the data consistence and availability, the analysis focused on the five major food crops of wheat, millet, maize, soybean and potato using the annual county-level data of 283 counties in the Loess Plateau. As farmland conversion was mostly implemented in hilly areas, the hilly region comprising all hilly counties (Fig. 1) was addressed separately.

\section{Data and methods}

\subsection{Study area}

The Loess Plateau $\left(33^{\circ} 41^{\prime}-41^{\circ} 16^{\prime} \mathrm{N}, 100^{\circ} 54^{\prime}-114^{\circ} 33^{\prime} \mathrm{E}\right)$ covers an area of $6.34 \times 10^{7} \mathrm{hm}^{2}$, with the hilly region (Fig. 1) covering about $4.54 \times 10^{7} \mathrm{hm}^{2}$, accounted for $71.61 \%$ of the total area. The hilly region is highly dissected by gullies and suffered from severe soil erosion (Tang et al., 2010). In 2014 , population in the plateau was totaled $1.10 \times 10^{8}, 174$ inhabitants $/ \mathrm{km}^{2}$. With a temperate semiarid to sub-humid climate, the annual mean temperature is $4.3^{\circ} \mathrm{C}-14.3^{\circ} \mathrm{C}$ and the mean annual precipitation varies from $200 \mathrm{~mm}$ in the northwest to $700 \mathrm{~mm}$ in the southeast (Wei et al., 2006). Influenced by monsoon climate, more than $70 \%$ of the annual precipitation falls in the rainy season from June to September. In the plateau, about 30\% of the area was farmland, $30 \%$ was forestland and shrubland, and 38\% was grassland before the GFG program implemented (Ping et al., 2013). Of the total farmland, about 65\% was slope land (Dang et al., 2011), and the remaining part was mainly distributed in tablelands and floodplains of the Yellow River and its tributaries of Weihe River and Fenhe River. The crop production is largely rainfed due to the slope limitation, but farmland in the floodplains is mostly accessible to irrigation. The main growing crops in the region are maize, wheat, soybean, potato and millet. 


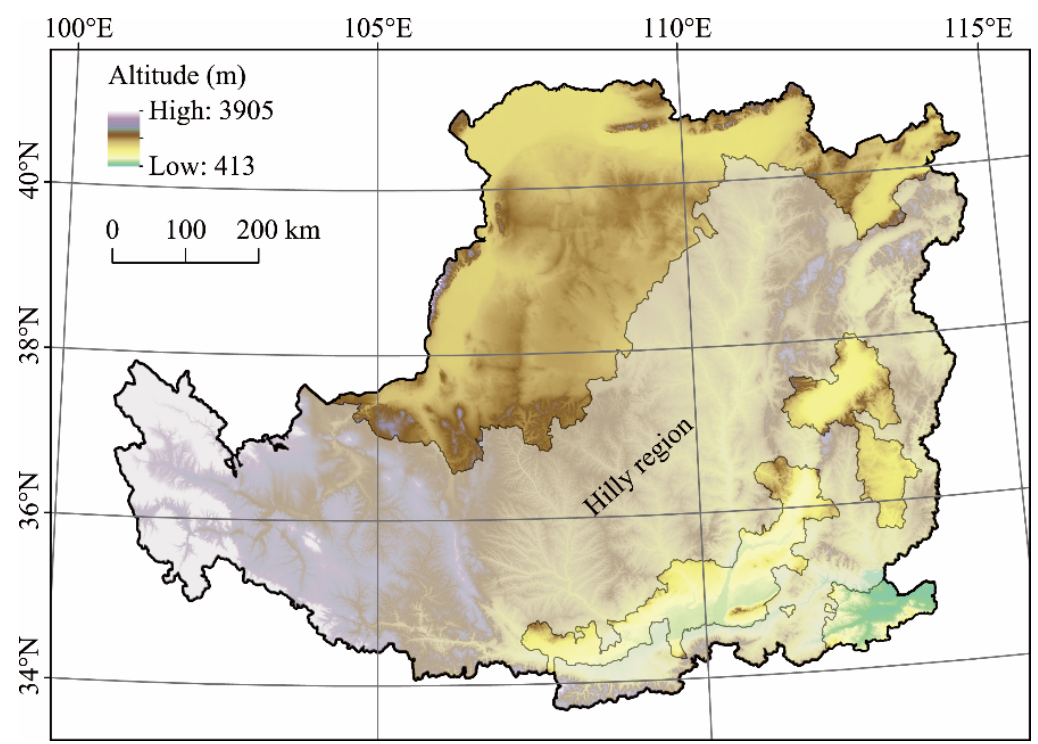

Fig. 1 Location of the Chinese Loess Plateau and its hilly region

\subsection{Data sources and preprocessing}

Annual total food crop production, sown area and yield of winter wheat, maize, soybean, millet and potato were obtained for 283 county-level administrative units from the local yearbooks of 19982014. To be comparable, the statistical yield of maize, soybean, potato and millet was converted to wheat equivalent, with the conversion coefficients of $1.01,1.42,0.23$ and 1.07 , respectively. These coefficients $\left(\mathrm{CF}_{i}\right)$ were calculated based on the content of energy and protein with the following equation (Ren and Hou, 1999):

$$
\mathrm{CF}_{i}=\frac{H_{i}}{H_{0}} \times 0.9+\frac{P_{i}}{P_{0}} \times 0.1,
$$

where $H_{i}$ and $P_{i}$ are the content of calories and protein in crop $i$, and $H_{0}$ and $P_{0}$ are the content of calories and protein in winter wheat, respectively.

\subsection{Quantifying factor contribution to total crop production and yield changes}

This study applied the logarithmic mean Divisia index model (LMDI) to calculate the contribution of mean crop yield and sown area to the FCP change and the refined Laspeyres index model (RLI) to calculate the contribution of yield of individual crops and cropping structure to the mean yield. These two models are commonly used methods of factor decomposition analysis that decompose the target variable into a number of factors through conversion of mathematical identity, and estimate the factor's contribution (Liu et al., 2013). Different from the often-used methods such as multiple regressions, the LMDI and RLI methods can quantify the contribution of each factor to the changes in total crop production (Jiang et al., 2013; Liu et al., 2013; Jin et al., 2014; Zhou et al., 2015).

The FCP ( $\mathrm{t})$ can be simply presented as a product of mean crop yield $\left(Y_{\mathrm{M}}, \mathrm{t} / \mathrm{hm}^{2}\right)$ and total sown area $\left(A, \mathrm{hm}^{2}\right)$ of all crops considered:

$$
\mathrm{FCP}=Y_{\mathrm{M}} \times A .
$$

The change in total FCP between the starting year 0 and year $t$, denoted as "FCP $\mathrm{FCP}^{0}$ ", can be approximately decomposed as two parts, i.e., contributed by changes in the mean crop yield and sown area, respectively:

$$
\mathrm{FCP}^{t}-\mathrm{FCP}^{0}=A^{t} \times\left(Y_{\mathrm{M}}^{t}-Y_{\mathrm{M}}^{0}\right)+Y_{\mathrm{M}}^{t} \times\left(A^{t}-A^{0}\right)+\varepsilon,
$$

where $\mathrm{FCP}^{t}$ and $\mathrm{FCP}^{0}$ are the total $\mathrm{FCP} ; A^{t}$ and $A^{0}$ are the total crop sown area; $Y_{\mathrm{M}}^{t}$ and $Y_{\mathrm{M}}^{0}$ are the mean crop yield in year $t$ and 0 , respectively; and $\varepsilon$ is the residual value and can be eliminated using 
the LMDI method (Ang, 2005) by converting Equation 3 to the form below:

$$
\mathrm{FCP}^{t}-\mathrm{FCP}^{0}=\frac{\left(\mathrm{FCP}^{t}-\mathrm{FCP}^{0}\right) \times\left(\ln Y_{\mathrm{M}}^{t}-\ln Y_{\mathrm{M}}^{0}\right)}{\ln \mathrm{FCP}^{t}-\ln \mathrm{FCP}^{0}}+\frac{\left(\mathrm{FCP}^{t}-\mathrm{FCP}^{0}\right) \times\left(\ln A^{t}-\ln A^{0}\right)}{\ln \mathrm{FCP}^{t}-\ln \mathrm{FCP}^{0}} .
$$

The two items on the right side represent the contribution of change in the $Y_{\mathrm{M}}$ and the $A$ to the change of total FCP. A positive value indicates a positive contribution, otherwise a negative contribution.

For the $Y_{\mathrm{M}}$, the RLI model was adopted to identify the contribution of different crops. The decomposed form is presented below:

$$
Y_{\mathrm{M}}=Y_{e}+S_{e}=\sum_{i=1}^{5} Y_{i} S_{i},
$$

where $Y_{i}$ is the yield $\left(\mathrm{t} / \mathrm{hm}^{2}\right)$ of crop $i$ and $S_{i}$ is the sowing proportion of crop $i$ as the total crop sown area; $Y_{e}$ is the total contribution by yield change of each crop; and $S_{e}$ is the total contribution by the change in the sown area between year 0 and $t$. Both of them can be decomposed as follows based on the RLI method (Sun, 1998):

$$
\begin{aligned}
& Y_{e}=\sum_{i=1}^{5}\left(Y_{i}^{t}-Y_{i}^{0}\right) S_{i}^{0}+\frac{1}{2} \sum_{i=1}^{5}\left(Y_{i}^{t}-Y_{i}^{0}\right)\left(S_{i}^{t}-S_{i}^{0}\right) \\
& S_{e}=\sum_{i=1}^{5}\left(S_{i}^{t}-S_{i}^{0}\right) Y_{i}^{0}+\frac{1}{2} \sum_{i=1}^{5}\left(Y_{i}^{t}-Y_{i}^{0}\right)\left(S_{i}^{t}-S_{i}^{0}\right)
\end{aligned} .
$$

\section{Results}

\subsection{Spatiotemporal changes of sown area and crop production}

During 1998-2014, total crop sown area in the plateau showed a phased variation characteristic (Fig. 2a) and can be divided into three stages, i.e., decreasing (1998-2003), restoring (2003-2010) and stabilizing (2010-2014) stages. In the first or early implementing stage of GFG program, the sown area quickly decreased from $1.08 \times 10^{7} \mathrm{hm}^{2}$ in 1998 to $8.94 \times 10^{6} \mathrm{hm}^{2}$ in 2003 , reduced by $17.3 \%$, and then gradually restored in the second stage to $1.03 \times 10^{7} \mathrm{hm}^{2}$ in $2010,95.5 \%$ of that in 1998. Thereafter, the crop sown area was slightly decreased to $1.02 \times 107 \mathrm{hm}^{2}$ in $2014,94.6 \%$ of the area in 1998, relatively stabilized in the last stage. Similarly, total sown area in the hilly region of the plateau was rapidly reduced by $16.2 \%$ during $1998-2003$, and then gradually restored to $5.93 \times 10^{6} \mathrm{hm}^{2}$ in 2010 from the lowest of $5.46 \times 10^{6} \mathrm{hm}^{2}$ in 2003 . After 2010 , the sown area slightly decreased to $5.86 \times 10^{6} \mathrm{hm}^{2}$ in 2014, 10.1\% lower than that in 1998 (Fig. 2b). During 1998-2014, the reduction of crop sown area occurred mainly in counties of hilly areas, whereas the expansion was mainly in the northwest, and river basins and low hilly areas in the northeastern and southeastern parts (Fig. 3). For individual crops, maize and potato in the plateau kept an expanding trend in sown area, increased by $68.8 \%$ and $29.2 \%$, while wheat, soybean and millet decreased by $36.2 \%, 38.3 \%$ and $48.6 \%$, respectively.

Crop yield showed a different variation pattern. Mean yield of the five major crops declined from $3461 \mathrm{~kg} / \mathrm{hm}^{2}$ in 1998 to $3151 \mathrm{~kg} / \mathrm{hm}^{2}$ in 2000 , and then rapidly increased to $3904 \mathrm{~kg} / \mathrm{hm}^{2}$ in 2004 . Followed by a stagnation period from 2004 to 2007, the yield turned to rapidly growing again and reached $4791 \mathrm{~kg} / \mathrm{hm}^{2}$ in 2014 (Fig. 2). In the hilly region, the mean crop yield showed a similar changing trend, but the variation amplitude was lower (Fig. 2). Yield of individual crops all showed a similar improving trend. From 1998 to 2014, mean yield of wheat in the plateau increased from 3290 to $3990 \mathrm{~kg} / \mathrm{hm}^{2}$, maize from 5398 to $6122 \mathrm{~kg} / \mathrm{hm}^{2}$, soybean from 1519 to $2110 \mathrm{~kg} / \mathrm{hm}^{2}$, and potato from 2895 to $3534 \mathrm{~kg} / \mathrm{hm}^{2}$.

As a result of changes in the crop sown area and yield, total FCP in the whole plateau quickly declined in the first three years, from $3.74 \times 10^{7} \mathrm{t}$ in 1998 to $3.18 \times 10^{7} \mathrm{t}$ in 2001 . Since then, the FCP generally maintained a continuously growing trend (Fig. 2), increased by $54.4 \%$ to $4.90 \times 10^{7} \mathrm{t}$ in 2014. From 1998 to 2014, mean growth rate of total FCP in the plateau was $1.71 \%$ per year and 
varied greatly among different counties. In 28 counties, the annual growth rate exceeded 5.0\%, and in 76 counties it was between $2.5 \%-5.0 \%$, in 36 counties $1.5 \%-2.5 \%$ and in 56 counties less than $1.5 \%$ (Fig. 4). In the remaining 87 counties, about $30 \%$ of the total, mainly located in the southern part of the region, the FCP was in a decreasing trend.
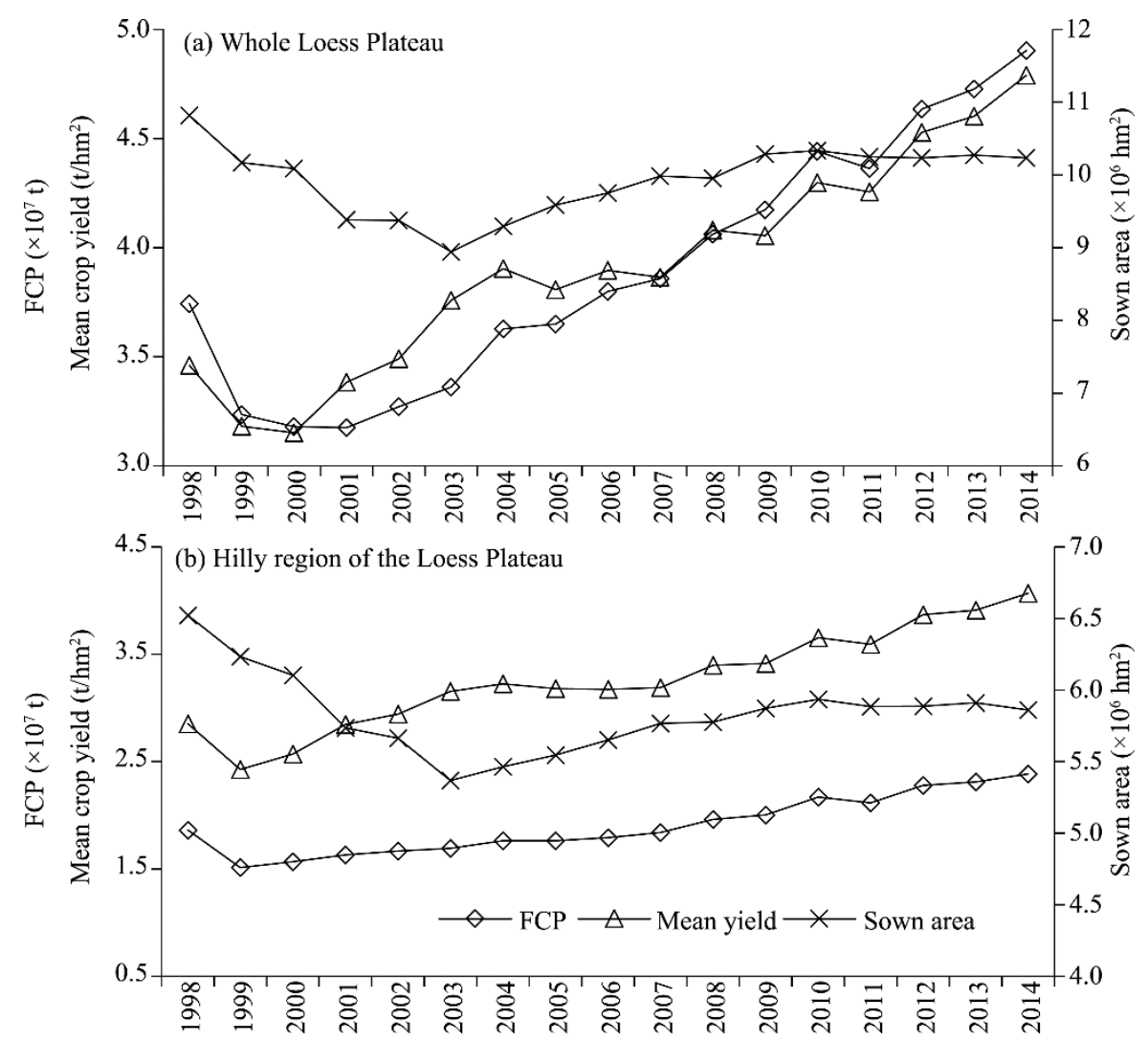

Fig. 2 Annual variation of the total food crop production (FCP), mean crop yield and total crop sown area during 1998-2014 in the whole Loess Plateau (a) and the hilly region (b). The FCP and mean crop yield were converted to wheat equivalent.

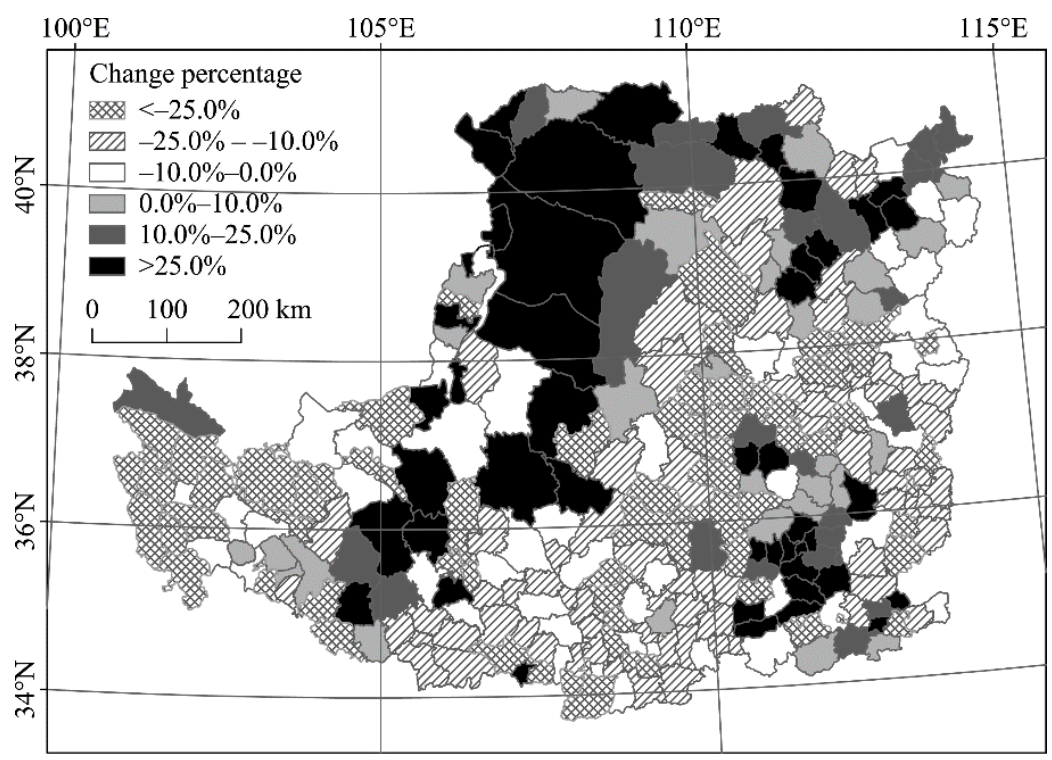

Fig. 3 Spatial variation of total crop sown area changes in the Loess Plateau between 1998 and 2014 


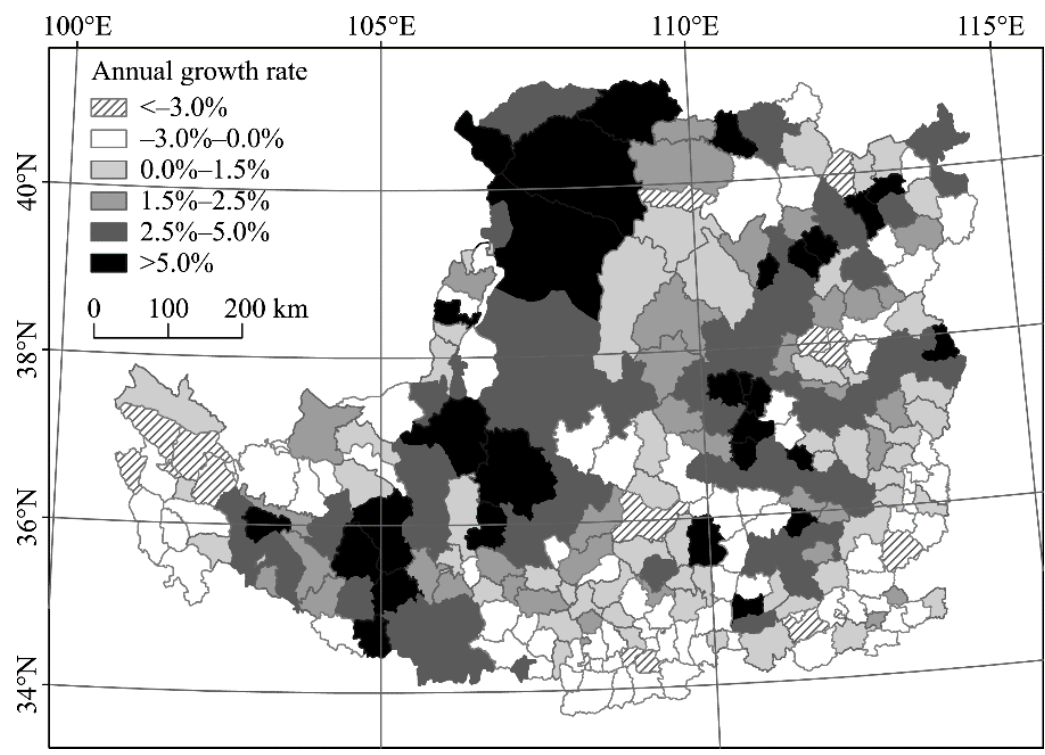

Fig. 4 Spatial distribution of annual growth rate of total FCP in the Loess Plateau during 1998-2014

\subsection{Contribution of crop yield and sown area changes to the total FCP}

The LMDI decomposition analysis results (Table 1) indicated that, associated with the yield improvement, the growth rate of total FCP should be $2.00 \%$ per year during 1998-2014 for the whole plateau and $2.26 \%$ for the hilly region, but it decreased to $1.71 \%$ and $1.65 \%$, respectively, due to the negative contribution of the sown area shrinkage. During 1998-2003, sown area shrinkage was significant, which caused the FCP declined by $3.11 \%$ per year, more than twofold of the positive contribution of the yield increase in the plateau. From 2004 to 2010, the crop sown area and yield were both increased, which jointly stimulated a quicker growth of FCP. During 20102014, the FCP growth was mostly contributed by the improved crop yield (Table 1).

Table 1 Annual growth rate of total FCP and the contributions by the changes in yield and crop sown area in the whole and hilly region of the Loess Plateau

\begin{tabular}{|c|c|c|c|c|}
\hline \multirow{3}{*}{ Loess Plateau } & \multirow{3}{*}{ Period } & \multicolumn{3}{|c|}{ Annual growth rate of total FCP (\%) } \\
\hline & & \multirow{2}{*}{ Total } & \multicolumn{2}{|c|}{ Induced by changes in } \\
\hline & & & Yield & Sown area \\
\hline \multirow{4}{*}{ Whole region } & $1998-2003$ & -1.61 & 1.50 & -3.11 \\
\hline & 2003-2010 & 3.58 & 1.74 & 1.84 \\
\hline & 2010-2014 & 2.04 & 2.22 & -0.19 \\
\hline & 1998-2014 & 1.71 & 2.00 & -0.29 \\
\hline \multirow{4}{*}{ Hilly region } & 1998-2003 & -1.21 & 2.00 & -3.21 \\
\hline & 2003-2010 & 3.18 & 1.91 & 1.27 \\
\hline & 2010-2014 & 1.97 & 2.22 & -0.25 \\
\hline & 1998-2014 & 1.65 & 2.26 & -0.61 \\
\hline
\end{tabular}

Note: FCP, food crop production.

During 1998-2014, all crop yields were significantly improved. Meanwhile the cropping structure was obviously adjusted, characterized by expansion of maize and potato, and shrinkage of wheat, soybean and millet (Table 2). These changes jointly contributed to the mean crop yield growth, of which the yield improvement contributed $62 \%$ and $68 \%$, and the cropping adjustment contributed $38 \%$ and $32 \%$ in the whole plateau and hilly regions, respectively. Among the three stages, the contribution of individual crops varied due to the changes in yield and sown area, but maize showed a positive contribution to the mean crop yield in all stages, implying that maize played a key role in the increase of total FCP (Table 3). 
Table 2 Yield and sown area changes of the major crops during different stages in the whole and hilly region of the Loess Plateau

\begin{tabular}{|c|c|c|c|c|c|c|c|c|c|c|c|}
\hline \multirow{2}{*}{$\begin{array}{l}\text { Loess } \\
\text { Plateau }\end{array}$} & \multirow{2}{*}{ Period } & \multicolumn{5}{|c|}{ Annual growth rate of yield (\%) } & \multicolumn{5}{|c|}{ Annual growth rate of sown area (\%) } \\
\hline & & $\mathrm{W}$ & $\mathrm{Ma}$ & $\mathrm{S}$ & $\mathrm{P}$ & $\mathrm{Mi}$ & $\mathrm{W}$ & $\mathrm{Ma}$ & $\mathrm{S}$ & $\mathrm{P}$ & $\mathrm{Mi}$ \\
\hline \multirow{4}{*}{$\begin{array}{l}\text { Whole } \\
\text { region }\end{array}$} & $1998-2003$ & -0.96 & -0.44 & 2.43 & 3.61 & 8.52 & -3.80 & 0.95 & -3.73 & 2.06 & -11.62 \\
\hline & $2003-2010$ & 2.90 & 1.38 & 1.78 & -1.56 & -3.12 & -0.96 & 4.87 & -0.30 & 2.15 & 2.60 \\
\hline & 2010-2014 & 1.32 & 1.16 & 1.17 & 2.94 & 7.57 & -2.54 & 2.03 & -4.32 & -0.46 & 0.10 \\
\hline & $1998-2014$ & 1.41 & 0.83 & 2.04 & 1.41 & 3.76 & -2.54 & 3.23 & -2.73 & 1.60 & -2.85 \\
\hline \multirow{4}{*}{$\begin{array}{l}\text { Hilly } \\
\text { region }\end{array}$} & $1998-2003$ & 0.45 & 0.03 & 4.01 & 5.39 & 6.34 & -4.29 & -0.77 & -2.57 & 3.11 & -8.75 \\
\hline & 2003-2010 & 3.36 & 1.69 & 1.95 & -1.09 & -0.47 & -1.64 & 4.71 & -0.07 & 2.69 & 0.92 \\
\hline & 2010-2014 & 1.53 & 1.29 & 1.36 & 3.20 & 2.62 & -2.29 & 2.28 & -3.01 & -0.11 & -2.07 \\
\hline & $1998-2014$ & 2.19 & 1.19 & 2.73 & 2.33 & 2.79 & -2.96 & 2.61 & -1.83 & 2.33 & -3.26 \\
\hline
\end{tabular}

Note: W, wheat; Ma, maize; $\mathrm{S}$, soybean; P, potato; Mi, millet.

Table 3 Contributions of individual crop yield and sown area to mean crop yield changes in the whole and hilly region of the Loess Plateau

\begin{tabular}{|c|c|c|c|c|c|c|c|c|c|c|c|c|c|}
\hline \multirow{2}{*}{ Period } & \multirow{2}{*}{$\begin{array}{c}\text { A } \\
(\%)\end{array}$} & \multicolumn{6}{|c|}{ Contributed by yield changes (\%) } & \multicolumn{6}{|c|}{ Contributed by changes in cropping structure (\%) } \\
\hline & & $\mathrm{T}$ & $\mathrm{W}$ & $\mathrm{Ma}$ & $\mathrm{S}$ & $\mathrm{P}$ & $\mathrm{Mi}$ & $\mathrm{T}$ & $\mathrm{W}$ & $\mathrm{Ma}$ & $\mathrm{S}$ & $\mathrm{P}$ & $\mathrm{Mi}$ \\
\hline \multicolumn{14}{|c|}{ Whole region of the Loess Plateau } \\
\hline $1998-2003$ & 1.53 & 40.70 & -31.12 & -13.71 & 6.20 & 23.94 & 55.39 & 59.30 & -17.30 & 121.00 & -1.85 & 31.45 & -73.99 \\
\hline 2003-2010 & 1.99 & 63.24 & 46.55 & 40.86 & 3.17 & -9.64 & -17.70 & 36.62 & -47.77 & 86.40 & -4.24 & 1.80 & 0.43 \\
\hline 2010-2014 & 1.86 & 74.30 & 10.42 & 29.74 & 1.71 & 12.04 & 20.40 & 25.88 & -25.52 & 57.68 & -5.57 & -1.26 & 0.54 \\
\hline 1998-2014 & 2.01 & 62.00 & 15.29 & 24.58 & 3.30 & 5.93 & 12.89 & 38.00 & -32.80 & 84.01 & -4.21 & 7.07 & -16.08 \\
\hline \multicolumn{14}{|c|}{ Hilly region of the Loess Plateau } \\
\hline $1998-2003$ & 2.05 & 66.72 & -5.94 & -9.76 & 10.17 & 38.81 & 33.44 & 33.12 & -23.35 & 53.54 & 1.71 & 42.80 & -41.58 \\
\hline 2003-2010 & 2.17 & 64.82 & 37.94 & 39.39 & 4.74 & -10.01 & -7.25 & 35.24 & -42.29 & 79.64 & -3.69 & 11.66 & -10.08 \\
\hline 2010-2014 & 1.85 & 72.25 & 10.45 & 29.64 & 2.70 & 20.99 & 8.47 & 27.93 & -20.00 & 59.37 & -5.50 & 0.72 & -6.67 \\
\hline 1998-2014 & 2.27 & 67.64 & 17.24 & 23.57 & 5.34 & 12.99 & 8.50 & 32.38 & -29.69 & 66.74 & -2.98 & 15.06 & -16.75 \\
\hline
\end{tabular}

Note: $A$, annual growth rate; $\mathrm{T}$, total contribution of the five crops.

\section{Discussion}

\subsection{Impacts of GFG program on the crop production}

Based on the county-level land use survey of China completed in 1996, the total farmland in the Loess Plateau was $1.61 \times 10^{7} \mathrm{hm}^{2}$, of which $1.32 \times 10^{7} \mathrm{hm}^{2}$ was distributed in the hilly areas and not accessible to irrigation (Li, 2000). From literature data (Li, 2000; Liu et al., 2013; Li, 2014), about $33 \%-40 \%$ of the farmlands, i.e., $4.35 \times 10^{6}-5.27 \times 10^{6} \mathrm{hm}^{2}$ in the hilly areas were steep farmlands with the slope steepness of more than $15^{\circ}$. These steep croplands are categorized as temporary farmlands (Li, 2014), temporarily used for growing some small crops of sesame, naked oats, and foxtail millet with very limited inputs. Excluding these temporary croplands, the total farmland in the plateau before the GFG policy enacted was around $1.08 \times 10^{7}-1.17 \times 10^{7} \mathrm{hm}^{2}$, close to the total sown area $\left(1.08 \times 10^{7} \mathrm{hm}^{2}\right)$ of major crops in 1998 . This implied that conversion of only steep slope farmlands should not significantly influence the sown area of major crops.

However, over-conversion of farmlands occurred during 1999-2003, resulted in the evident reduction of crop sown area (Fig. 2). After pilot demonstrations in the selected areas in 1999, the GFG program had been implemented in the whole China with a planned implementation period of 8 years. During the period, the farmers who return the steeply cultivated lands to forestland or grasslands can get an annual subsidy of $1.5 \mathrm{t}$ grains (or equivalent of money) per $\mathrm{hm}^{2}$. This subsidy was very attractive and thus stimulated serious over-conversion of farmlands, causing a quick decrease of crop sown area and thus a negative impact on food crop production. In 2003, total crop sown area of major crops in the Loess Plateau decreased by $17.3 \%$ compared to that in 1998 , and 
similarly, China's total crop production was reduced by $16.0 \%$ for the same period as well. Recognizing this serious problem, the Chinese government strictly regulated the scope of farmland conversion (Chen et al., 2016), and meanwhile enacted the policy to exempt from the agricultural tax and adopted direct subsidies to food crop production in 2004. As the subsidy supplied according to the sown area of food crops, the slope farmlands that are not mandated to be converted were gradually restored to grow food crops in the Loess Plateau. In addition, the Chinese government enhanced the support to make slope farmlands to terraces, which also contributed to the increase of crop sown area after 2003. Our team did an analysis on land use change between 2003 and 2009 for a typical hilly area of $900 \mathrm{~km}^{2}\left(36^{\circ} 45^{\prime} 15^{\prime \prime} \mathrm{N}-37^{\circ} 01^{\prime} 26^{\prime \prime} \mathrm{N}, 109^{\circ} 25^{\prime} 02^{\prime \prime} \mathrm{E}-109^{\circ} 45^{\prime} 22^{\prime \prime} \mathrm{E}\right)$ in northern Shaanxi Province using the $2.5 \mathrm{~m}$ resolution imagery data ( $\mathrm{Li}, 2014)$. It was found that the slope farmland was reduced by $32.2 \%$ in 2009 , but the terraced land increased by $33.6 \%$, of which $86.7 \%$ was converted from slope farmlands.

With the farmland conversion, crop sown area was reduced by $5.4 \%$ in the whole plateau and by $10.1 \%$ in the hilly region during 1998-2014. The reduction of crop sown area did not cause a corresponding decrease of total FCP, excepting the period 1999-2001 (Fig. 2). From 2002 onwards, total FCP in the plateau has maintained a quick growth and thus the food self-sufficiency has been improved, with the mean food grain per capita increased to $446 \mathrm{~kg}$ in 2014 from $376 \mathrm{~kg}$ in 1998 . This increase was contributed by the crop yield improvement, due to increased inputs and the adjustment of cropping structure, i.e., the replacement of traditionally growing crops of millet and wheat by higher yield maize crops (Table 3 ). In addition, terrace building and conversion of slope lands improved the land quality and reduced the surface water loss, and thus contributed to the yield increase. Observation data of Ansai County in northern Shaanxi Province during 1994-2001 showed that crop yield in terraced farmlands was $140 \%-200 \%$ higher than that in slope farmlands (Lu et al., 2011). A study in Dingxi of Gansu Province reported that when slope farmland was converted to terraces, the yield was increased by $600-1050 \mathrm{~kg} / \mathrm{hm}^{2}$ (Zhang, 2015).

In general, the GFG program had no significantly adverse impact on the crop production in the Loess Plateau. Recent studies for Ansai County by comparing the conditions before and after the GFG program implemented, obtained a similar conclusion that the food security was not negatively affected by the program (Han et al., 2014; Wang et al., 2014; Zhou et al., 2014). Another study for Huining County of Gansu Province by Wang et al. (2014) indicated that the agricultural inputs were markedly increased and thus obviously improved the crop productivity and food security level with the GFG implementation. Based on the survey data of 793 households in the five provinces of northwestern China, Su et al. (2011) found that the implementation of GFG program evidently improved the ecological conditions and rural livelihoods.

\subsection{Policy implications}

The implementation of GFG program has promoted restoration of the degraded environment in the Loess Plateau as reported by many studies, e.g., Fu et al. (2005), and Yang and Lu (2018). The results of this study suggest that the conversion of slope farmlands in a gradual and planned way could not affect the crop production and thus food security. The influence of reduced farmland area can be mitigated by the improvement of land productivity. The conversion of farmlands reduced the labour involved in cropping activities, and thus liberated the rural labour to seek off-farm employment. Several studies indicated that total income was increased for the most rural households that involved in the GFG program, mainly due to the increased off-farm income (Hong et al., 2008; Zhu and Wang, 2014; Yang et al., 2017).

With urbanization and young people moved to urban areas, population pressure in the plateau is expected to decrease, which provides an opportunity to further reduce the cultivation of slope farmlands. By reconnaissance surveys in 2017 in northern Shaanxi Province, we observed that abandonment of slope farmlands was quite often in the areas along the roads. However, there is also a risk of re-cultivation of the converted farmlands. Farmer surveys conducted in 2005 for 2000 households in 25 counties of northern Shaanxi Province indicated that $37.2 \%$ of farmers intended to re-cultivate the forested areas and grassland once the program's subsidy ends (Cao et al., 2009). Recognizing this risk, the Chinese government had extended an additional 8 years of subsidies for 
farmland conversion in 2010 to 2018, and has continued to support the conversion from 2019 onwards. To stabilize the achievements, the GFG should be set as a long-term strategic policy, by not only supporting the conversion of slope farmlands, but also helping the farmers to seek sustainable ways of land use to improve the income and livelihood. It is suggested that the national poverty eradication program currently practiced in the poor regions including the Loess Plateau could be incorporated into this strategy. This is helpful to further improve the natural environment and to consolidate the land rehabilitation achievements in the Loess Plateau, contributing to the national strategy of ecological civilization building.

Due to rainfall limitation under the semi-arid climate, afforestation can cause soil desiccation problems (Wang et al., 2008). Some studies indicate that the Loess Plateau is probably reaching its sustainable limit of water resources for supporting tree growth (Feng et al., 2016), and thus tree vegetation should not be further expanded (Chen et al., 2015). Therefore, the strategy of GFG program should be targeted to promote the conversion of slope farmlands to grasslands. Further afforestation in the Loess Plateau should be cautioned to avoid the negative impacts.

\section{Conclusions}

With the implementation of GFG program, the total crop sown area in the Loess Plateau quickly decreased by $17.3 \%$ to $8.94 \times 10^{6} \mathrm{hm}^{2}$ from 1998 to 2003 , then gradually restored to $1.03 \times 10^{7} \mathrm{hm}^{2}$ in 2010 , and thereafter relatively stabilized. In the hilly region of the plateau, the sown area rapidly reduced by $16.2 \%$ during $1998-2003$ to $5.46 \times 10^{6} \mathrm{hm}^{2}$, followed by a restoration to $5.93 \times 10^{6} \mathrm{hm}^{2}$ in 2010 , and then slightly decreased to $5.86 \times 10^{6} \mathrm{hm}^{2}$ in 2014 , reduced by $10.1 \%$ compared to that in 1998. By contrast, the total crop production generally showed an increasing trend, excepting the early three years for the whole and hilly region of the Loess Plateau. Our analyses indicate that the increase of total crop production was mainly contributed by the yield improvement and adjustment of cropping structure, while changes in the total sown area had a minor influence. This implies that the GFG program has no significant impact on the total crop production, as the reduced crop production by farmland area shrinkage has greatly been compensated by the yield improvement and adjustment of cropping structure. It is suggested that the GFG program should be set as a longterm strategy by incorporating the poverty eradication program to promote the transformation of land use patterns, as to simultaneously realize the aims of environmental restoration and livelihood improvement of local people. The slope farmland conversion should be prioritized to grasslands.

\section{Acknowledgements}

This work was jointly supported by the National Natural Science Foundation of China (41671093), and the National Key R\&D Program of China (2017YFA0604701, 2012CB955304). We thank the three anonymous reviewers for their critical comments and constructive suggestions.

\section{References}

Ang B W. 2005. The LMDI approach to decomposition analysis: A practical guide. Energy Policy, 33(7): 867-871.

Cao S, Chen L, Yu X. 2009. Impact of China's Grain for Green project on the landscape of vulnerable arid and semi-arid agricultural regions: A case study in northern Shaaxi Province. Journal of Applied Ecology, 46(3): 536-543. (in Chinese)

Cao S X, Xu C G, Li C, et al. 2009. Attitudes of farmers in China's northern Shaanxi Province towards the land-use changes required under the Grain for Green Project, and implications for the project's success. Land Use Policy, 26(4): 1182-1194.

Chen H, López-Carr D, Tan Y, et al. 2016. China's grain for green policy and farm dynamics: simulating household land-use responses. Regional Environmental Change, 16(4): 1147-1159.

Chen Y, Wang K, Lin Y, et al. 2015. Balancing green and grain trade. Nature Geoscience, 8: 739-741.

Cheng L S. 2014. Evaluation of the impacts of Grain for Green Project on the environmental, economic and social benefits in Mizhi County of Loess Plateau. Journal of West China Forestry Science, 4: 117-122. (in Chinese)

Dang W, Hao F, Luo X. 2011. Governance model research of slope cropland in the Loess Plateau. In: Proceedings of Symposium on Integrated Soil Erosion Management of Slope Cropland. Beijing: Chinese Society for Soil and Water Conservation, 11-23. 
(in Chinese)

Deng L, Shuangguan Z P. 2011. Food security and farmers' income: Impacts of the grain for green programme on rural households in China. Journal of Food, Agriculture \& Environment, 9(3-4): 826-831.

Feng X, Fu B, Piao S, et al. 2016. Revegetation in China's Loess Plateau is approaching sustainable water resource limits. Nature Climate Change, 6: 1019-1022.

Feng Z M, Yang Y Z, Zhang Y Q, et al. 2005. Grain-for-green policy and its impacts on grain supply in West China. Land Use Policy, 22(4): 301-312.

Fu B J, Zhao W W, Chen L D, et al. 2005. Assessment of soil erosion at large watershed scale using RUSLE and GIS: A case study in the Loess Plateau of China. Land Degradation \& Development, 16(1): 73-85.

Guo L Y, Di L P, Li G, et al. 2015. GIS-based detection of land use transformation in the Loess Plateau: A case study in Baota District, Shaanxi Province, China. Journal of Geographical Sciences, 25(12): 1467-1478.

Han L, Zhu H L. 2014. Effects of the Grain for Green project on grain production in Ansai county. 2014 Seventh International Joint Conference on Computational Sciences and Optimization. Beijing: IEEE, 684-687.

Hong R, Li B, Chong J. 2008. Effects of the Grain for Green Project on Rural Household's Life - A case study in Huangfuchuan watershed. Forestry Economics, 2: 17-20, 29. (in Chinese)

Jiang S M, Jin J L, Xu H, et al. 2013. Fluctuations effect analysis of grain yield per hectare based on empirical mode decomposition and set pair analysis. Transactions of the Chinese Society of Agricultural Engineering, 4: 213-221. (in Chinese)

Jin T, Zhang M, Lu J F. 2014. Decomposition analysis for spatial variation of grain yield per hectare in Jiangsu province. Geography and Geo-Information Science, 5: 48-53. (in Chinese)

Li S, Wei L, Fu B., et al. 2016. Vegetation changes in recent large-scale ecological restoration projects and subsequent impact on water resources in China's Loess Plateau. Science of the Total Environment, 569-570: 1032-1039.

Li W J. 2014. Assessing effect of the ecological building on vegetation restoration and aridity in Northern Shaanxi Province. PhD Dissertation. Beijing: University of Chinese Academy of Sciences, 128. (in Chinese)

Li W J, Lu C H. 2015. Aridity trend and response to vegetation restoration in the loess hilly region of northern Shaanxi Province. Journal of Geographical Sciences, 25(3): 289-300.

Li Y. 2000. Land Resources of China. Beijing: China Dadi Press, 568-570. (in Chinese)

Liu C. 2015. Estimating the effects of the sloping land conversion to forestland on grain production. Forestry Economics, 37(9): 51-65. (in Chinese)

Liu W C, Yan C Z, Qin Y W, et al. 2013. Cropland dynamics and its influence on the productivity in recent 20 years in Northern Shaanxi, China. Journal of Natural Resources, 28(8): 1373-1382. (in Chinese)

Liu Y, Gao B B, Pan Y C, et al. 2013. Influencing factor decomposition of grain production at county level in Huang-Huai-Hai region based on LMDI. Transactions of the Chinese Society of Agricultural Engineering, 29(21): 1-10. (in Chinese)

Liu Z, Li B. 2012. Spatial and temporal changes in grain production before and after implementation of Grain for Green project in Loess Plateau region. Transactions of the Chinese Society of Agricultural Engineering, 28(11): 1-8. (in Chinese)

Liu Z, Huang F, Li B G. 2013. Investigating contribution factors to China's grain output increase in period of 2003 to 2011. Transactions of the Chinese Society of Agricultural Engineering, 29(23): 1-8. (in Chinese)

Lu C H, Wang Q, Ma J F. 2011. Effects of the ecological construction in the hilly Loess Plateau. Journal of Arid Land Resources and Environment, 25(10): 28-31. (in Chinese)

Ping Z, Wen A, Zhang X, et al. 2013. Soil conservation and sustainable eco-environment in the Loess Plateau of China. Environmental Earth Sciences, 68(3): 633-639.

Ran S H, Lu C H, Wang Q. 2010. Impacts of ecological cropland-conversion on land use and ecosystem service functions in Ansai County. China Population, Resources and Environment, 20(3): 111-116. (in Chinese)

Ren J Z, Hou F J. 1999. Change traditional thinking about food grain production and use food equivalent in yield measurement. Acta Prataculturae Sinica, (8): 55-75. (in Chinese)

Su Y X, Peng D L, Xie C, et al. 2011. Achievements and trends of grain for green program in northwest China - analysis based on surveying 793 rural households in 5 provinces in northwest China and inner Mongolia autonomous region. Bulletin of Soil \& Water Conservation, 31(6): 199-202. (in Chinese)

Sun J W. 1998. Changes in energy consumption and energy intensity: A complete decomposition model. Energy Economics, 20(1): 85-100.

Tang Q, Xu Y, Liu Y. 2010. Spatial difference of land use change in Loess Plateau region. Journal of Arid Land Resources and Environment, 24(8): 15-21. (in Chinese)

Wang C, Zhen L, Du B Z, et al. 2014. Assessment of the impact of Grain for Green project on farmers' livelihood in the Loess Plateau. Chinese Journal of Eco-Agriculture, 22(7): 850-858. (in Chinese) 
Wang F, Li R, Wen Z M. 2002. Survey of factors affecting eco-environmental benefits of cropland conversion: A case-based study on cropland conversion experimental station in Ansai county. Bulletin of Soil and Water Conservation, 22(3): 1-4. (in Chinese)

Wang L, Wang Q, Wei S, et al. 2008. Soil desiccation for Loess soils on natural and regrown areas. Forest Ecology and Management, 255(7): 2467-2477.

Wang X H, Shen J X, Zhang W. 2014. Emergy evaluation of agricultural sustainability of Northwest China before and after the grain-for-green policy. Energy Policy, 67(4): 508-516.

Wei J, Zhou J, Tian J L, et al. 2006. Decoupling soil erosion and human activities on the Chinese Loess Plateau in the $20^{\text {th }}$ century. Catena, 68(1): 10-15.

Xu Y, Ma D G, Guo T Y. 2006. Effects of actualized ecological de-farming policy and its influences on farmer's livelihood in the Loess Plateau. Research of Soil and Water Conservation, 13(5): 255-258. (in Chinese)

Xu Z G, Xu J T, Deng X Z, et al. 2006. Grain for Green versus grain: Conflict between food security and conservation set-aside in China. World Development, 34(1): 130-148.

Yang K J, Lu C H. 2018. Evaluation of land-use change effects on runoff and soil erosion of a hilly basin - the Yanhe River in the Chinese Loess Plateau. Land Degradation and Development, 29(4): 1211-1221.

Yang M, Wang F, Wang L Q, et al. 2017. Investigation on changes of households involved in the Grain for Green Project in loess hilly region within recent 15 years. Journal of Arid Land Resources and Environment, 31(6): 44-50. (in Chinese)

Ye H. 2009. Study on objectives coupling of grain subsidy policy and policy of returning cultivated land to forest: Analysis based on behaviors of farmer households. Technology Economics, 28(7): 32-37. (in Chinese)

Yue Y J, Yan W N, Wang X H, et al. 2014. Impacts of the ecological restoration program on regional ecosystem services: A case of Yanchi county, Ningxia Autonomous Region. Journal of Arid Land Resources and Environment, 28(2): 60-67. (in Chinese)

Zhang H. 2015. An analysis on the efficiency and problems of terrace building in Guansu Region of the Loess Plateau. Gansu Science and Technology, 31(4): 7-9. (in Chinese)

Zhao G, Mu X, Wen Z, et al. 2013. Soil erosion, conservation and eco-environment changes in the Loess Plateau of China. Land Degradation \& Development, 24(5): 499-510.

Zhou H, van Rompaey A, Wang J A. 2009. Detecting the impact of the "Grain for Green" program on the mean annual vegetation cover in the Shaanxi province, China using SPOT-VGT NDVI data. Land Use Policy, 26(4): 954-960.

Zhou P, Wen A B, Yan D C, et al. 2014. Changes in land use and agricultural production structure before and after the implementation of grain for green program in Western China - taking two typical counties as examples. Journal of Mountain Science, 11(2): 526-534.

Zhou Z G, Zheng M L. 2015. Influential factors decomposition for China's grain yield based on logarithmic mean Divisia index method. Transactions of the Chinese Society of Agricultural Engineering, 31(2): 1-6. (in Chinese)

Zhu C J, Wang S J. 2014. An analysis on the impact of slope cropland conversion to forests on the income of rural households in west region of China. Agrotechnical Economy, (10): 58-66. (in Chinese)

Zuo D P, Xu Z X, Yao W Y, et al. 2016. Assessing the effects of changes in land use and climate on runoff and sediment yields from a watershed in the Loess Plateau of China. Science of the Total Environment, 544: 238-250. 